\title{
Moist Secret Mass; Buschke-Lowenste in Tumor: A Report of Three Cases
}

\author{
Mehmet Zafer Sabuncuoglu'1, Aylin Sabuncuoglu'2, Girayhan Celik ${ }^{1}$, Isa Sozen ${ }^{3}$, Recep Cetin ${ }^{1}$ \\ ${ }^{1}$ General Surgery Department, Faculty of Medicine, Suleyman Demirel University, Isparta, Turkey \\ ${ }^{2}$ Anesthesia and Critical Care Unit, Gulkent State Hospital, Isparta, Turkey \\ ${ }^{3}$ General Surgery Department, Ankara Numune Education and Researh Hospital, Ankara, Turkey \\ Email: drmehmetzafer@yahoo.com
}

Received 13 June 2014; revised 12 July 2014; accepted 11 August 2014

Copyright (C 2014 by authors and Scientific Research Publishing Inc.

This work is licensed under the Creative Commons Attribution International License (CC BY).

http://creativecommons.org/licenses/by/4.0/

(c) (i) Open Access

\begin{abstract}
Buschke-Löwenstein tumor (BLT), or giant condyloma acuminatum, is a rare sexually transmitted disease with a potentially fatal course. The virus responsible for condyloma is human papillomavirus, usually serotype 6 or 11. A BLT is always preceded by condyloma acuminatum and may occur at any age after puberty. It is characterized by invasive growth and recurrence after treatment, and malignant transformation is possible. There is no general agreement on the choice of treatment for this tumor. Wide radical excision with plastic reconstruction of skin defects seems to be the best treatment, while adjuvant therapies, such as radiotherapy and immunotherapy, may achieve good results, but their effectiveness is still unclear. We report 3 cases of 32- and 40-yearold males and a 38-year-old female with an approximate 5-year history of a perianal BLT.
\end{abstract}

\section{Keywords}

Buschke-Löwenstein Tumor, Giant Condyloma, Case Report

\section{Introduction}

It was first described as a penile lesion by Abraham Buschke in 1896, then in 1925, Buschke and his assistant, Löwenstein reported on giant condyloma acuminatum (GCA) as benign carcinoma-like condyloma acuminatum [1]. The first description of anorectal GCA was by Dawson et al. in 1965 [2]. However, some authors classify the GCA as a low-grade squamous cell carcinoma (SCC) with minimal metastasis risk and a verrucous carcinoma (VC) of the anogenital region [3]. Ackermann coined the term VC for well-differentiated, low-grade carcinoma of oral mucosal viral warts [4].

It is a rare sexually transmitted disease with an incidence of probably $0.1 \%$ in the general population. The

How to cite this paper: Sabuncuoglu, M.Z., Sabuncuoglu, A., Celik, G., Sozen, I. and Cetin, R. (2014) Moist Secret Mass; Buschke-Lowenste in Tumor: A Report of Three Cases. Case Reports in Clinical Medicine, 3, 474-478.

http://dx.doi.org/10.4236/crcm.2014.38104 
incidence has sharply increased [1], with an estimated 2 to 3 million newly reported cases each year [5]. GCA is a rare lesion tending to present in the fifth decade with a 2.7:1 male:female ratio. The most distinctive feature of GCA is malignant behaviour, i.e. aggressive local growth by compression, destruction and infiltration of neighbouring tissues and lack of spontaneous resolution. In addition, GCA has a high propensity for local tumrence and considerable risk of neoplastic transformation into fully invasive squamous cell carcinoma (SCC) [6].

Most authors recommend early control of local disease by radical excision, and eventual abdominoperineal resection in cases of recurrence, pelvic invasion or malignant transformation [7]. Management is still a challenge as response is often poor, and regardless of the type of treatment, recurrence rates as high as $67 \%$ and mortality rates of $20 \%$ - 30\% have been reported [8]. The cases are reported here of 2 males aged 32 and 40 years and a 38-year-old female with a perianal Buschke-Löwenstein tumor.

\section{Case Report}

The cases are presented here of 2 circumcised, heterosexual males aged 32 and 40 years with a 4-year history and a 38-year-old female with a 5-year history of a perianal BLT (first male: $12 \mathrm{~cm} \times 10 \mathrm{~cm}$ and $10 \mathrm{~cm} \times 8 \mathrm{~cm}$, second male: $10 \mathrm{~cm} \times 6 \mathrm{~cm}$ and $10 \mathrm{~cm} \times 8 \mathrm{~cm}$, female: $6 \mathrm{~cm} \times 6 \mathrm{~cm}$ and $8 \mathrm{~cm} \times 6 \mathrm{~cm}$ ) bilateral exophytic cauliflower-like verrucous mass of the anal verge and with no notable medical history (Figure 1).

The patients reported foul-smelling discharge, pruritus and pain. All 3 patients were married and denied any sexual promiscuity. A full screening for other sexually transmitted infections was negative. The tumors had evolved progressively for about 4 - 5 years and resulted in itching and bleeding. The patients underwent an examination under general anesthesia to exclude involvement of the anal canal and rectum. The perianal lesions were then surgically removed by full-thickness excision. The entire wound was left open and allowed to heal by secondary intention (Figure 2). The pathologic analysis of the specimen confirmed the diagnosis of condyloma acuminatum, with moderate degree of dysplasia of the epithelium with koilocytosis atypia, acanthosis, and parakeratosis. At the 1-month follow-up, the lesions had almost completely disappeared, with minute smooth pigmented papules remaining (Figure 3).

\section{Discussion}

BLT is an aggressive, rapidly-growing, fungating variant of condyloma. The aggressive nature of the lesion may cause multiple sinuses or fistula tracts that may invade deeply into the fascia, muscle, or rectum. This may result in inflammation, infection or hemorrhage.

Risk factors for human papilloma virus (HPV) transmission are: multiple sexual partners, prostitution, homosexuality, lack of hygiene, and chronic genital infections. BLT is always preceded by condyloma acuminatum, and the immune system is probably suppressed. It can be associated with congenital or acquired immunodeficiency (AIDS) including alcoholism, diabetes, or chemotherapy with immunosuppressive therapy. Males are more frequently involved, the $\mathrm{M} / \mathrm{F}$ sex ratio being 3 . It is located on the penis in $81 \%$ to $94 \%$ of cases, in the anorectal area in $10 \%$ to $17 \%$, and in the urethra in $5 \%$. In females, the location is chiefly the vulva (90\%) and

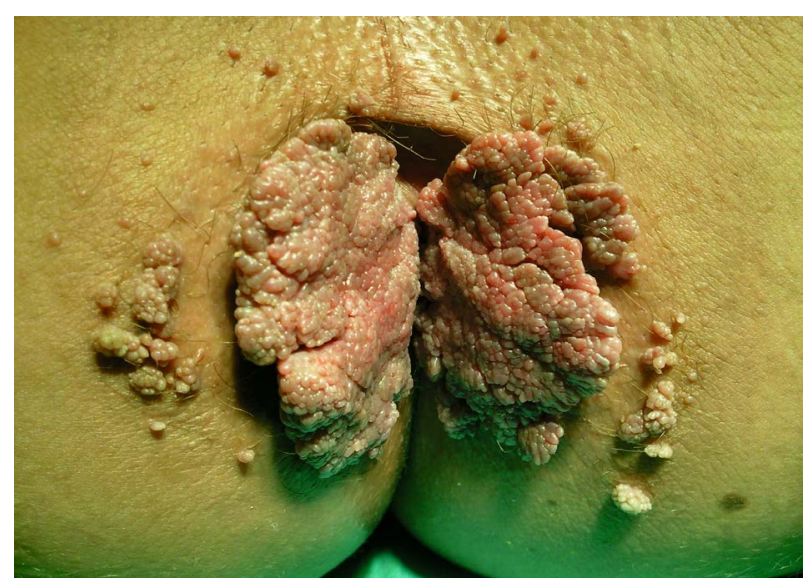

Figure 1. Voluminous, exophytic, cauliflower-like. 


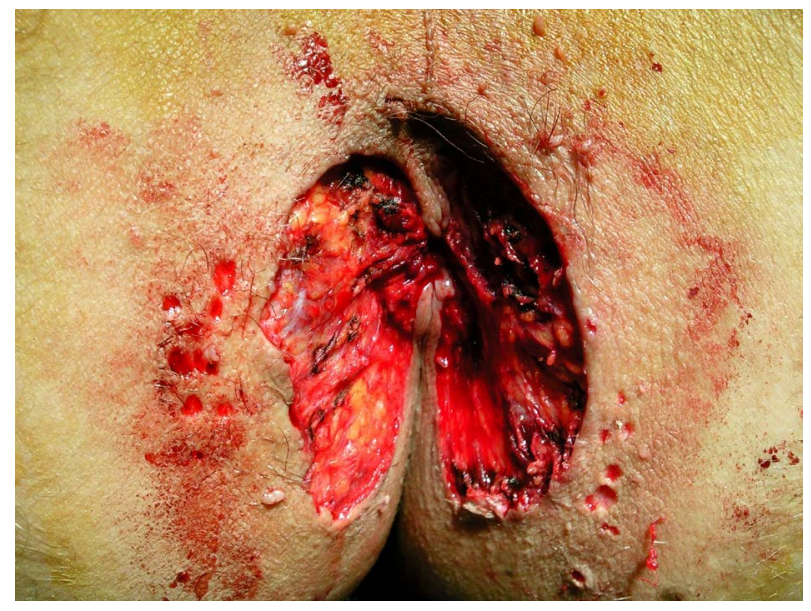

Figure 2. Extended excision of mass verrucous mass.

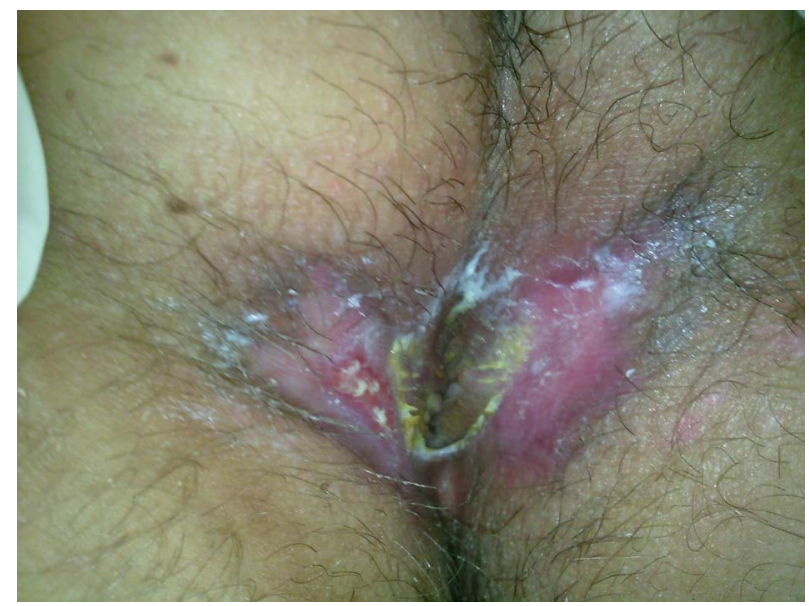

Figure 3. One month later.

an anorectal location is less frequent. Clinically it appears as a large, cauliflower-like, white or yellow tumor of papillomatous and irregular surface, eventually exceeding $10 \mathrm{~cm}^{2}$. It can still be very difficult to distinguish BLT from ordinary condylomas or well-differentiated squamous cell carcinomas. There is probably a viral etiology (HPV subtypes 6 - 11 and 13 - 15).

Spontaneous regression is exceptional, and recurrence after an incomplete excision is frequent. Bleeding, infiltration of the tumor basis, or lymph node enlargement may cause the clinician to suspect a malignant transformation into micro-invasive carcinoma or into well-differentiated keratinizing squamous cell carcinoma, which occurs in about $30 \%$ of cases.

Surgery is the treatment of choice and is effective in the early stages of the disease. Excision must be wide and the Mohs technique is often used [9]. The wide local excision of the tumor with subsequent histological examination of the resection margins is the most suitable method of treatment for BLT, similar to treatment of other malignancies. In literature reviews, surgical treatment has been reported to lead to a recurrence rate of $50 \%$ whereas the overall rate of recurrence (including surgery, topical treatment and radiochemotherapy) is $67 \%$ [10]. Non-surgical treatments are claimed to increase recurrence rates due to insufficient tumor destruction and are usually used to shrink the tumor before surgery.

Radiotherapy is rarely used usually only when excision is not recommended or in recurrences. It may also be indicated to complement surgery in the case of an incomplete excision. It has been suspected of being responsible for the alteration of BLT into aplastic carcinoma.

Chemotherapy may be helpful in reducing the tumor mass [9]. Topical application of podophyllin has been shown to be helpful for ordinary condyloma acuminata but does not control giant condyloma acuminata given 
its large size. Immunotherapy with autologous vaccine from the patient's own condyloma has been reported with good success rates and has been suggested for giant condyloma acuminata and recurrent lesions [11]. Topical chemotherapy with 5-fluororacil has been used for the treatment of genital condylomata, but seems to yield poor outcomes with giant lesions.

Recent publications have reported on the high efficacy of combined radiochemotherapy (vinblastine, methotrexate and bleomycin) in the treatment of head and neck VCs [12].

Imiquimod 5\% cream represents a novel treatment for GCA and is approved by the US Food and Drugs Administration [13]. Imiquimod serves as a potent antiviral and antitumoral agent and confers protective cytotoxic immune response against HPV [13]. Imiquimod offers the advantages of less tissue damage, self-applicability on an outpatient basis and lower recurrence rates [13].

Total regression of a recurrent giant perianal condyloma treated with radiotherapy has also been reported [14]. Interferon has been used via a topical, intralesional, or systemic route [15]. Systemic interferon may be considered for those lesions too large to be injected or excised surgically or in conjunction with other treatment to lower the recurrence rate. Alternative methods include cryotherapy, laser and electrocauterization.

\section{Conclusions}

BLT is mostly seen in young men and the most important morbidity is local invasion and recurrens in this patient. Thus, patient should be carefully evaluated for the purpose of detecting the tumor invasion.

The optimal treatment for BLT is still being debated because of the lack of a consistent series of patients. Upon correct diagnosis, giant condyloma acuminata should be treated with radical surgical excision, whenever feasible abdominoperineal resection or fecal diversion can also be used.

Chemotherapy with 5-fluorouracil and radiation therapy may be used in cases of recurrence or extensive pelvic disease. In summary, good viroimmunological control may be insufficient to control HPV infections. Continuous screening for these infections must be maintained as part of ongoing care. In our opinion the radical surgical excision of the tumor may be considered as the first-choice therapy. But controlled, prospective studies are necessary to further define the nature and treatment.

\section{Conflict of Interest Statement}

Mehmet Zafer Sabuncuoglu and the co-authors have no conflict of interest.

\section{References}

[1] Buschke, A. and Löwenstein, L. (1925) Über Carcinomähnliche Condylomata Acuminata des Penis. Klinische Wochenschrift, 4, 1726-1728. http://dx.doi.org/10.1007/BF01728480

[2] Dawson, D.F., Duckworth, S.K., Bernhardt, H., et al. (1965) Giant Condyloma and Verrucous Carcinoma of the Genital Area. Archives of Pathology, 79, 225-231.

[3] Schwartz, R.A. (1995) Verrucous Carcinoma of the Skin and Mucosa. Journal of the American Academy of Dermatology, 32, 1-21. http://dx.doi.org/10.1016/0190-9622(95)90177-9

[4] Ackermann, L.V. (1948) Verrucuos Carcinoma of the Oral Cavity. Surgery, 23, 670-678.

[5] Shulman, S., Phair, J. and Sommers, H. (editors) (1992) The Biological and Clinical Basis for Infectious Disease. 4th Edition, Saunders, Philadelphia.

[6] Martin, J.M., Molina, I., Monteagudo, C., Marti, N., Lopez, V. and Jorda, E. (2008) Buschke-Lowenstein Tumor. Journal of Dermatological Case Reports, 2, 60-62. http://dx.doi.org/10.3315/jdcr.2008.1019

[7] Chu, Q.D., Vezeridis, M.P., Libbey, N.P. and Wanebo, H.J. (1994) Giant Condyloma Acuminatum (BuschkeLöwenstein Tumor) of the Anorectal and Perianal Regions: Analysis of 42 Cases. Diseases of the Colon \& Rectum, 37, 950-957. http://dx.doi.org/10.1007/BF02052606

[8] Renzi, A., Giordano, P., Renzi, G., et al. (2006) Buschke-Lowenstein Tumor Successful Treatment by Surgical Excision Alone: A Case Report. Surgical Innovation, 13, 69-72. http://dx.doi.org/10.1177/155335060601300111

[9] Qarro, A., et al. (2005) Tumeur de Buschke-Loewenstein à localisation anorectale (à propos de trois cas). Annales de Chirurgie, 130, 96-100. http://dx.doi.org/10.1016/j.anchir.2004.06.005

[10] Trombetta, L.J. and Place, R.J. (2001) Giant Condyloma Acuminatum of the Anorectum: Trends in Epidemiology and Management: Report of a Case and Review of the Literature. Diseases of the Colon \& Rectum, 44, 1878-1886. http://dx.doi.org/10.1007/BF02234473 
[11] Wiltz, O.H., Torregosa, M. and Wiltz, O. (1995) Autogenous Vaccine: The Best Therapy for Perianal Condyloma Acuminatua? Diseases of the Colon \& Rectum, 38, 838-841. http://dx.doi.org/10.1007/BF02049840

[12] Strojan, P., et al. (2005) Radiochemotherapy with Vinblastine, Methotrexate and Bleomycin in the Treatment of Verrucous Carcinoma of the Head and Neck. Journal of Surgical Oncology, 92, 278-283. http://dx.doi.org/10.1002/jso.20422

[13] Ting, P.T. and Dytoc, M.T. (2004) Therapy of External Anogenital Warts and Molluscum Contagiosum: A Literature Review. Dermatologic Therapy, 17, 68-101. http://dx.doi.org/10.1111/j.1396-0296.2004.04009.x

[14] Sobrado, C.W., Mester, M., Nadalin, W., et al. (2000) Radiation-Induced Total Regression of a Highly Recurrent Giant Perianal Condyloma. Report of a Case. Diseases of the Colon \& Rectum, 43, 257-260. http://dx.doi.org/10.1007/BF02236991

[15] Trofatter, K.F. (1991) Interferon Treatment of Anogenital Human Papillomavirus Related Disease. Dermatol Clin, 9, 343-352. 
Scientific Research Publishing (SCIRP) is one of the largest Open Access journal publishers. It is currently publishing more than 200 open access, online, peer-reviewed journals covering a wide range of academic disciplines. SCIRP serves the worldwide academic communities and contributes to the progress and application of science with its publication.

Other selected journals from SCIRP are listed as below. Submit your manuscript to us via either submit@scirp.org or Online Submission Portal.
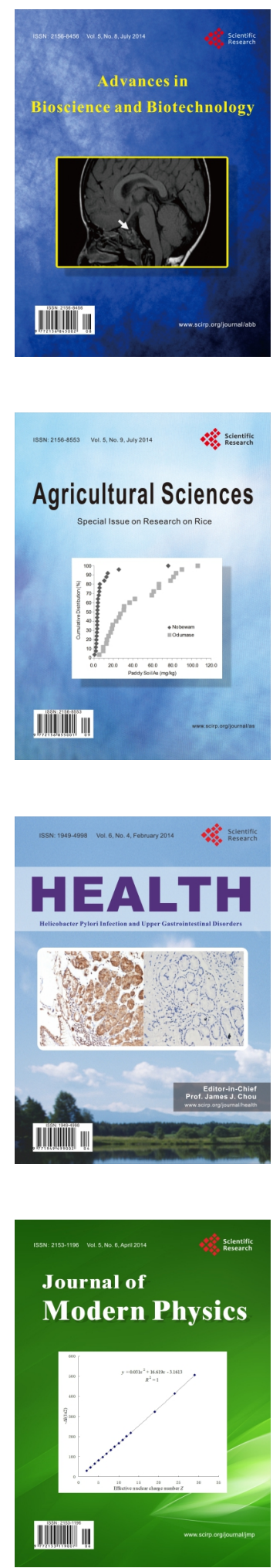
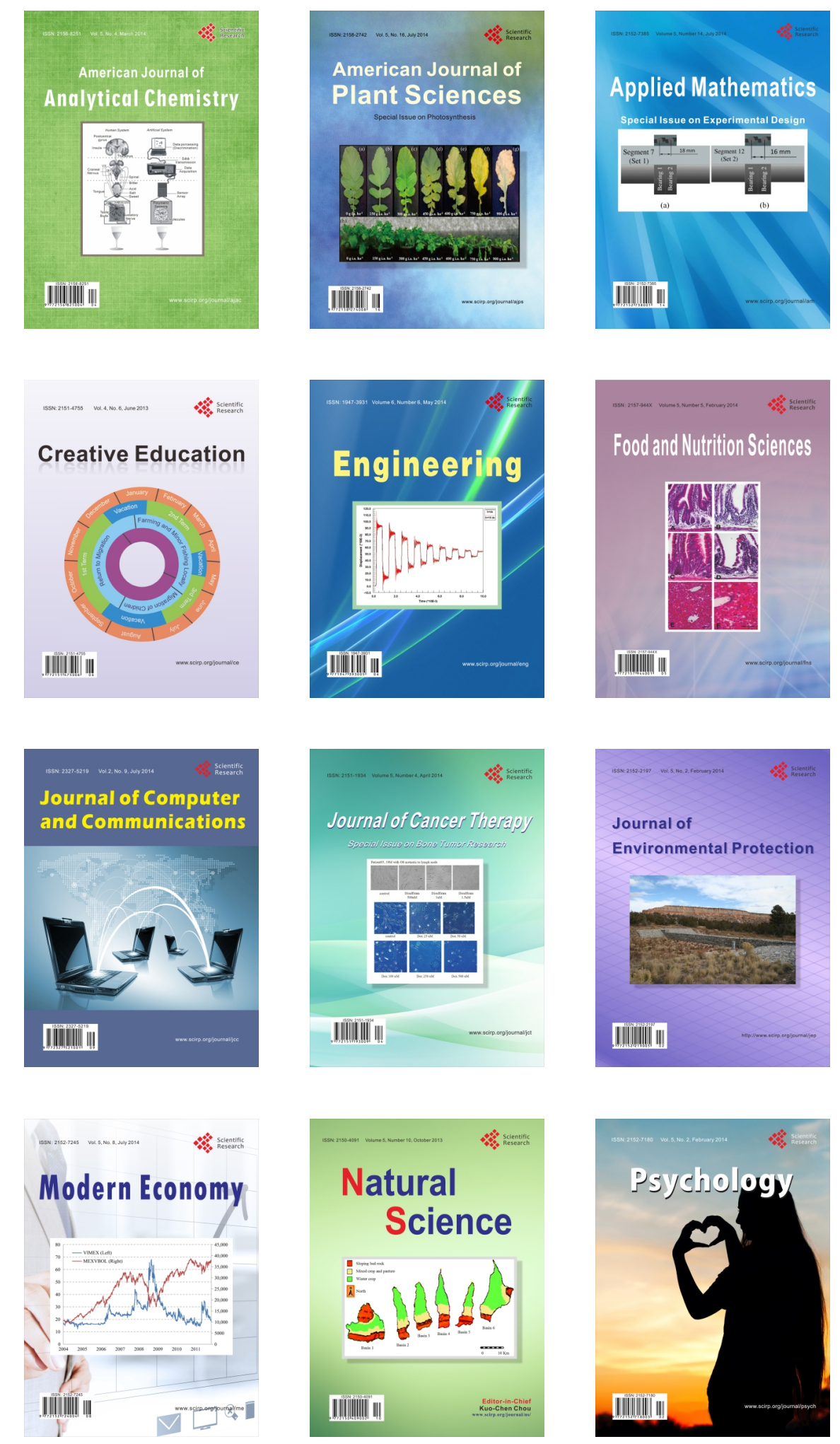